\title{
Uso de elementos da paisagem como ferramenta para a escolha de áreas adequadas para implantação de loteamentos urbanos - estudo de caso
}

\author{
Dagoberto Port* \\ Fabiane Fisch ${ }^{* *}$
}

\section{Resumo}

A partir da segunda metade do século XX, os países em desenvolvimento tiveram um grande aumento no número de habitantes em áreas urbanas, sem o correspondente aumento do número de moradias. Como consequência, praticamente em todos os países do terceiro mundo, um grande contingente de pessoas vive em áreas sem infraestrutura e com conflitos ambientais. Neste contexto, a questão habitacional é um dos principais desafios a serem vencidos pelos governantes de todos os países. No presente trabalho avaliamos a adequação de seis áreas, na província de Kwanza Sul, Angola. Realizamos a avaliação utilizando elementos da paisagem como ferramenta para a determinação de sua adequação para a implantação de loteamentos. Das seis áreas avaliadas consideramos duas adequadas para o fim a que se destinam, outras três adequadas com restrições e uma avaliamos como inadequada para fins de loteamentos urbanos.

Palavras-chave: Análise da paisagem; Loteamentos; Angola; África.

Use of landscape elements as a tool for the selection of appropriate areas for urban lots deployment - case study

\footnotetext{
** Universidade do Vale do Itajaí (UNIVALI) - Novo Hamburgo-RS (dagoberto_port@hotmail.com).

**** Universidade do Vale do Itajaí (UNIVALI) - Novo HamburgoRS (fabianebarragens@hotmail.com)
}

Geosul, Florianópolis, v. 30, n. 60, p 207-224, jul./dez. 2015 
PORT, D. \& FISCH, F. Uso de elementos da paisagem como ferramenta...

\section{Abstract}

From the second half of the twentieth century, developing countries had a large increase in the number of inhabitants in urban areas without a corresponding increase in public services. As a result, in almost all third world countries, a large contingent of people lives in areas without infrastructure and with environmental conflicts. In this context, the housing issue is one of the main challenges to be overcome by governments of all countries. In this paper we evaluated the suitability of six areas in the province of Kwanza Sul, Angola. We performed the evaluation using landscape features of each area as a tool to determine its suitability for deploying urban settlements. Of the six areas evaluated we consider two suitable for the purpose it was intended, other three appropriate with restrictions and the last one assessed as unsuitable for urban lots.

Key words: Landscape analysis; Allotments; Angola; Africa.

\section{Introdução}

A partir da segunda metade do século XX, os países em desenvolvimento tiveram um grande incremento no número de habitantes em áreas urbanas, sem o correspondente aumento dos serviços públicos, entre eles as moradias. Como consequência, praticamente em todas as nações do terceiro mundo, um grande contingente de pessoas vive em áreas sem infraestrutura básica, muitas vezes inadequadas e com conflitos ambientais (ABREU, 1987). Seguindo esta tendência, a rápida urbanização nos países africanos, associada com condições econômicas desfavoráveis, tornou praticamente impossível prever as necessidades habitacionais da população, resultando em uma ocupação desordenada das cidades, forçando as pessoas a residir em aglomerados, favelas e assentamentos informais (BOADI et al., 2005). Neste contexto, a questão habitacional é um dos principais desafios a serem vencidos pelos governantes de todos os países, em especial aqueles em 
PORT, D. \& FISCH, F. Uso de elementos da paisagem como ferramenta...

desenvolvimento. Preocupado com esta questão em seu país, o Governo da República de Angola lançou no ano de 2009, o Programa Nacional de Urbanismo e Habitação (PNUH), que visa promover o bem-estar da população, fornecendo habitações adequadas a preço razoável para os cidadãos. De acordo com este programa, está prevista a construção de um milhão de novas casas naquele país até 2012 (ANGOLA, 2011). Por outro lado, conciliar este desafio de ter moradias dignas para todos, sem provocar danos ambientais é algo extremamente difícil, pois a habitação com qualidade é uma necessidade que deve ser satisfeita sem comprometimento dos ecossistemas existentes (FLORIM \& QUELHAS, 2004). Infelizmente, a questão ambiental, na escolha de áreas para a implantação de empreendimentos habitacionais, é em geral, relegada ao segundo plano, sendo a seleção dos locais, muitas vezes, feita com base em outros critérios, em especial os econômicos, em detrimento dos ambientais. Neste sentido, no presente trabalho avaliamos a adequação de seis áreas definidas como Reservas Fundiárias, na província de Kwanza Sul, Angola, no âmbito do PNUH daquele país, utilizando elementos da paisagem de cada uma como ferramenta para a determinação de sua adequação para a implantação de loteamentos.

\section{Material e métodos}

\section{Área de estudo}

Para a realização deste trabalho estudamos as características da paisagem de seis áreas (Sumbe, Sumbe I, Porto Amboim, Waku Kungo, Kibala e Amboim-Gabela), todas localizadas na província de Kwanza Sul, em Angola (Figura 1). Estes locais avaliados constituem-se em Reservas Fundiárias do Governo da República de Angola, instituídos pelos Decretos 107/08 e 108/08 de 26 de setembro de 2008, com a finalidade de implementação de loteamentos urbanos. 
PORT, D. \& FISCH, F. Uso de elementos da paisagem como ferramenta...
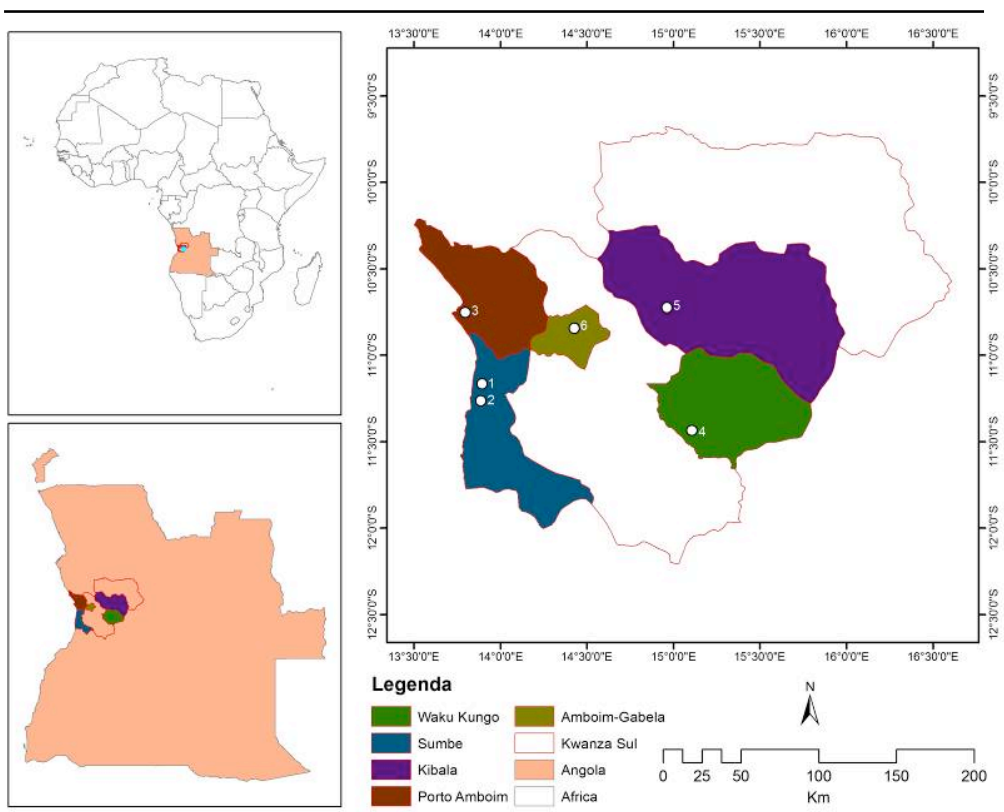

Figura 1: Mapa de localização da República de Angola, da Província de Kwanza Sul, dos municípios e das áreas avaliadas ( $1=$ Sumbe; 2 = Sumbe I; 3 = Porto Amboim; 4 = Waku Kungo; 5 = Kibala; $6=$ Amboim-Gabela).

A seguir descrevemos as principais características de cada uma das Reservas Fundiárias avaliadas.

\section{Sumbe}

A Reserva Fundiária de Sumbe, com uma área de 4.371 ha e 25.835,23 m de perímetro, localiza-se no município de Sumbe, distante aproximadamente $6 \mathrm{~km}$ da sede municipal, junto a Estrada Nacional $\mathrm{n}^{\circ} 100$, no sentido Sumbe-Luanda. O acesso a reserva é facilitado, além da Estrada Nacional, por diversas vias secundárias que cortam a mesma (Figura 2). Nesta região são desenvolvidas diversas atividades de subsistência, por parte de moradores da 
PORT, D. \& FISCH, F. Uso de elementos da paisagem como ferramenta...

própria reserva e do entorno, entre estas podemos destacar: extração de lenha, construção de represas para contenção de águas pluviais, agricultura e pecuária.

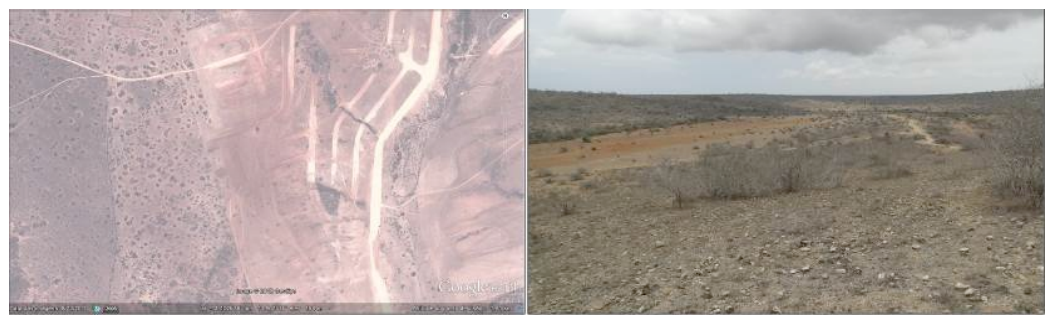

Figura 2: Vista geral da Reserva Fundiária de Sumbe (Fonte: imagem de satélite, Google Earth ${ }^{\mathrm{TM}}$, à esquerda e foto feita pelos autores, à direita).

A Reserva Fundiária de Sumbe encontra-se numa região de limite de rochas de idade variando de Proterozóicas até Cretácicas, ocorrendo ainda sedimentos recentes - quaternários. Localiza-se na faixa litoral, apresentando um relevo relativamente plano. Os solos são Arídicos Tropicais, caracterizados por serem solos de ocorrência normal nos climas secos (árido e semiárido), em que a fração fina é dominada por argila, com proporção variável de minerais, fortemente saturados em bases e elevada capacidade de troca catiônica, podendo apresentar profundidade variável, além de horizontes de acumulação de calcário ou gesso. Apresentam coloração pardo-acinzentada e menos vezes pardo-avermelhada (DINIZ, 2005). A área pertence a bacia do rio Cambongo-Negunza, entre as bacias dos rios Cuvo-Queve e Cubal-Quicombo, porém não existe nenhum curso de água permanente na mesma (AMARAL, 2006). A Reserva Fundiária de Sumbe localiza-se no bioma Zambezeano, o qual ocupa mais de $85 \%$ do país (ROOSBROECK et al., 2006), na zona de domínio da vegetação caracterizada como Savana com ou sem árvores. A cobertura vegetal é um mosaico de savanas, estepes e balcedos xerófitos, com ou sem árvores dispersas, sublitorais (BARBOSA, 1970). Esta 
PORT, D. \& FISCH, F. Uso de elementos da paisagem como ferramenta...

zona possui uma flora de porte herbáceo/arbustivo, xerófita, com alguns exemplares de porte arbóreo, destacando-se entre estes o embondeiro (Adansonia digitada), palmeiras e exemplares de Euphorbiaceae. Apesar da dominância da vegetação herbáceo/ arbustiva, existem grandes extensões de solo exposto, o que contribui para a aceleração dos processos erosivos. $\mathrm{O}$ aspecto geral da flora na área da reserva fundiária reflete as condições dominantes do clima local - tropical seco e de altitude, do tipo de estepe, com uma precipitação pluviométrica inferior à evaporação, podendo-se observar representantes típicos deste clima, como cactáceas e agaváceas. A fauna desta região encontra-se totalmente descaracterizada, tendo sido registrados apenas exemplares da avifauna e alguns répteis (lagartos), além de invertebrados.

\section{Sumbe I}

A Reserva Fundiária de Sumbe I, com área de 465,56 ha e $9.606,18 \mathrm{~m}$ de perímetro, localiza-se no município de Sumbe, distante aproximadamente $3 \mathrm{~km}$ da sede municipal, pela estrada Sumbe-Seles. Além desta via principal, o acesso a reserva é facilitado, por diversas vias secundárias que cortam a mesma. A área da Reserva Fundiária de Sumbe I possui instaladas várias residências, em pequenos conjuntos habitacionais, com uma distribuição desordenada. Nesta local são desenvolvidas atividades de subsistência, por parte de moradores da própria reserva e do entorno, dentre estas podemos destacar a agricultura e a pecuária (Figura 3).

Com relação aos aspectos da Geologia, Geomorfologia, Solos, Relevo, Hidrografia, Vegetação e Fauna, esta área é similar a anterior. 
PORT, D. \& FISCH, F. Uso de elementos da paisagem como ferramenta...

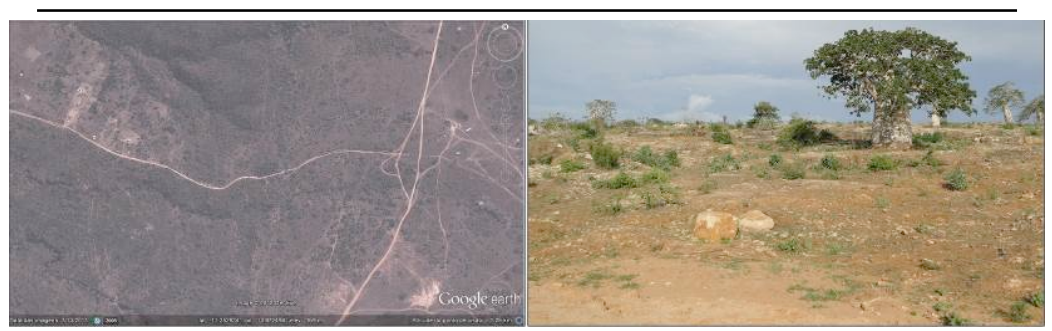

Figura 3: Vista geral da Reserva Fundiária de Sumbe I (Fonte: imagem de satélite, Google Earth ${ }^{\mathrm{TM}}$, à esquerda e foto feita pelos autores, à direita).

\section{Porto Amboim}

A Reserva Fundiária de Porto Amboim possui uma área de 372,69 ha e $8.050,98 \mathrm{~m}$ de perímetro. Localiza-se no município de Porto Amboim, distante aproximadamente $1 \mathrm{~km}$ da sede municipal, com acesso pela Estrada Nacional $\mathrm{n}^{\mathrm{o}} 100$, no sentido SumbeLuanda. Neste local desenvolvem-se atividades de subsistência por parte de moradores do entorno, tais como agricultura e pecuária (Figura 4).

Com relação aos aspectos da Geologia, Geomorfologia, Solos, Relevo, Vegetação e Fauna, esta área apresenta características similares a Reserva Fundiária de Sumbe. No que se refere a hidrografia, situa-se na bacia hidrográfica do rio CuvoQueve, porém na reserva não existem cursos de água permanentes.

\section{Waku Kungo}

A Reserva Fundiária de Waku Kungo possui uma área de 138,539 ha e 5.686,89 $\mathrm{m}$ de perímetro. Localiza-se no município da Cela (Waku Kungo) distante aproximadamente $3 \mathrm{~km}$ da sede municipal. O acesso a mesma é feito pela Estrada Nacional $\mathrm{n}^{\mathrm{o}} 240$ (Sumbe-Kibala) e Estrada Nacional no 120 (Kibala-Waku Kungo). Existem no local algumas residências, em pequenos conjuntos habitacionais, com uma distribuição desordenada. Na região são realizadas atividades de subsistência, por parte de moradores da 
PORT, D. \& FISCH, F. Uso de elementos da paisagem como ferramenta...

própria reserva e do entorno, destacando-se a vocação agrícola da mesma, tendo quase toda a sua extensão cultivada com milho, feijão, girassol, entre outras (Figura 5).

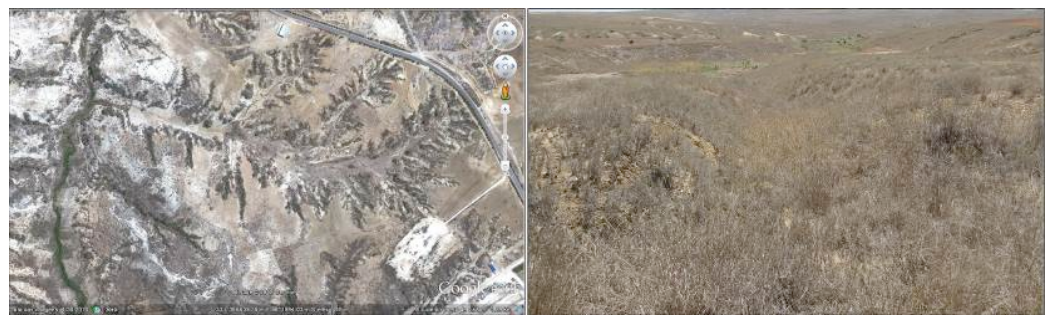

Figura 4: Vista geral da Reserva Fundiária de Porto Amboim (Fonte: imagem de satélite, Google Earth ${ }^{\mathrm{TM}}$, à esquerda e foto feita pelos autores, à direita).

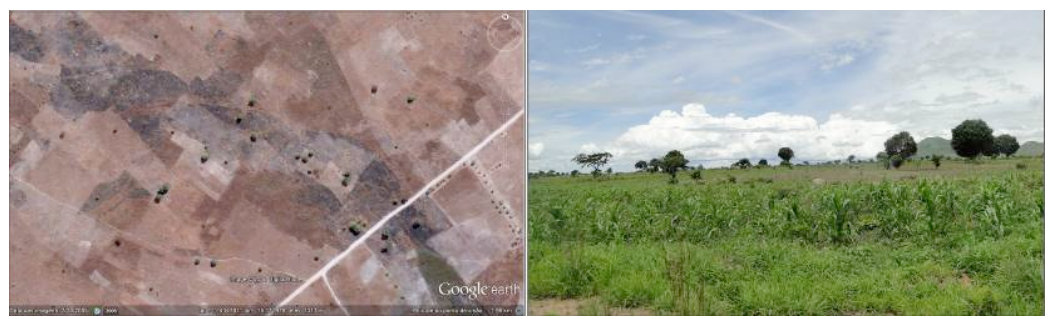

Figura 5: Vista geral da Reserva Fundiária de Waku Kungo (Fonte: imagem de satélite, Google Earth ${ }^{\mathrm{TM}}$, à esquerda e foto feita pelos autores, à direita).

A Reserva Fundiária de Waku Kungo encontra-se numa região de rochas de idade Proterozóicas do Grupo Oendolongo (ARAÚJO \& GUIMARÃES, 1992). É possível encontrar no local diversos afloramentos rochosos. A área da reserva apresenta um relevo relativamente plano, sendo os solos do tipo hidromórfico, que segundo o ZEE-RJ (2008) é um termo utilizado para solos formados sob condições de drenagem deficiente, em pântanos, brejos, áreas de surgência ou planícies, podendo ser orgânicos ou minerais. Com relação aos recursos hídricos, a região faz parte da 
PORT, D. \& FISCH, F. Uso de elementos da paisagem como ferramenta...

bacia hidrográfica do Cuvo-Queve, existindo na mesma uma área alagada. No que se refere a vegetação e a fauna, esta área apresenta condições similares a Reserva Fundiária de Sumbe.

\section{Kibala}

A Reserva Fundiária de Kibala tem uma área de 172, 34 ha e $6.051,22 \mathrm{~m}$ de perímetro e localiza-se no município de mesmo nome, do qual fica distante aproximadamente $1 \mathrm{~km}$ da sede municipal. O acesso ao local é feito pela Estrada Nacional $\mathrm{n}^{\mathrm{o}} 240$ (Sumbe-Kibala) e por estradas municipais não pavimentadas. A população do entorno da área utiliza algumas porções da mesma para agricultura de subsistência (Figura 6).

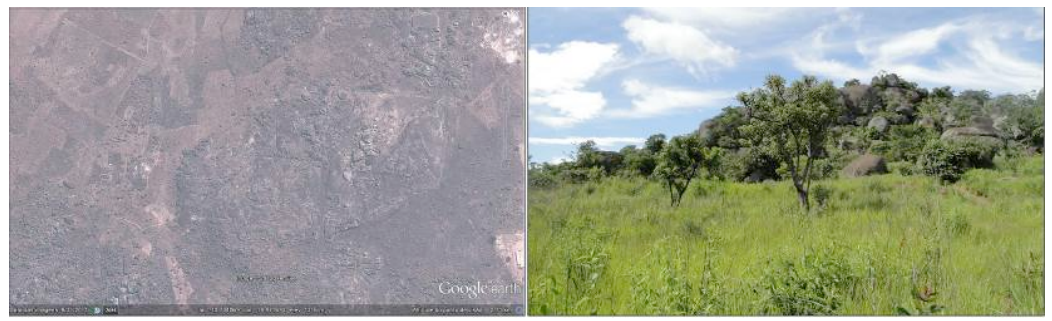

Figura 6: Vista geral da Reserva Fundiária de Kibala (Fonte: imagem de satélite, Google Earth ${ }^{\mathrm{TM}}$, à esquerda e foto feita pelos autores, à direita).

Este local também se encontra numa região de rochas de idade Proterozóica do Grupo Oendolongo (ARAÚJO \& GUIMARÃES, 1992). Caracteriza-se como uma zona de transição, apresentando um relevo muito acidentado, praticamente todo ocupado por afloramentos rochosos. Os solos classificam-se em ferralítico e paraferralítico, que são solos minerais de texturas fina ou média/fina (DINIZ, 2005). A Reserva Fundiária de Kibala localiza-se entre as bacias dos rios Longa e Nhia, sendo que na área da reserva não existem cursos de água permanentes. Durante a vistoria em campo, foi possível constatar a presença de um açude 
PORT, D. \& FISCH, F. Uso de elementos da paisagem como ferramenta...

temporário. Com relação a vegetação, o local localiza-se no bioma Zambezeano (ROOSBROECK et al., 2006), na zona de domínio da Floresta Aberta. De acordo com Diniz (1998), a Floresta Aberta constitui a comunidade fito-climática do centro planáltico angolano, que se caracteriza por uma alternância de estações chuvosa e seca, bem definidas e em geral correlacionando-se com solos Ferralíticos argiláceos. A flora da reserva fundiária encontrase pouco alterada por ação antrópica, principalmente em função de seu relevo, que praticamente inviabiliza sua ocupação. Tal situação permite que a área ainda tenha condições de abrigar uma diversidade de representantes da fauna.

\section{Amboim-Gabela}

A Reserva Fundiária de Amboim-Gabela tem uma área de 462,28 ha e $9.465,73 \mathrm{~m}$ de perímetro e localiza-se na cidade de Gabela, distante aproximadamente $1 \mathrm{~km}$ da sede municipal, junto a Estrada Nacional $\mathrm{n}^{\mathrm{o}} 240$, no sentido Sumbe-Gabela, sendo que possui instaladas inúmeras comunidades. Na área são desenvolvidas diversas atividades, por parte de moradores que ocupam a mesma. Dentre estas podemos destacar: agricultura e pecuária, que tem caráter familiar e são de subsistência, além de pequenos comércios (Figura 7).

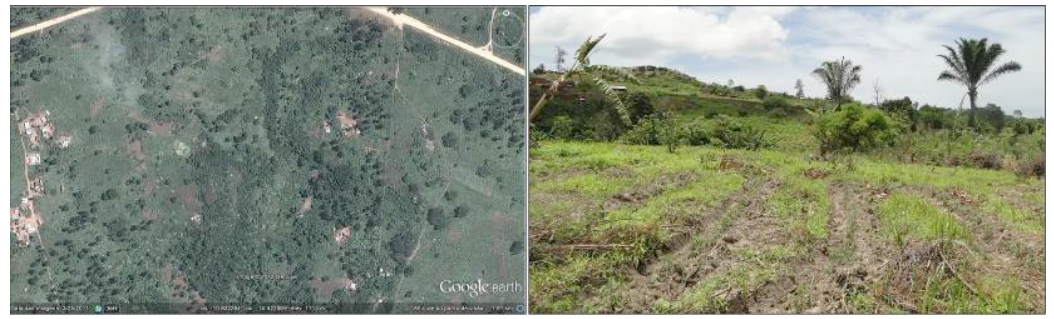

Figura 7: Vista geral da Reserva Fundiária de Amboim-Gabela (Fonte: imagem de satélite, Google Earth ${ }^{\mathrm{TM}}$, à esquerda e foto feita pelos autores, à direita). 
PORT, D. \& FISCH, F. Uso de elementos da paisagem como ferramenta...

A Reserva Fundiária de Amboim-Gabela encontra-se numa região de limite de rochas de idade Proterozóicas (Proterozóico Inferior, Grupo Oendolongo), com composição média e ácida (ARAÚJO \& GUIMARÃES, 1992). Na área é possível encontrar diversos afloramentos rochosos, sendo o relevo acidentado, com algumas áreas planas. A região situa-se na bacia hidrográfica do rio Cuvo-Queve, sendo que na área da reserva não existem cursos de água permanentes. Com relação a vegetação e a fauna, as características desta área são similares a anterior (Kibala).

\section{Métodos}

Para realização deste trabalho utilizamos mapas temáticos impressos (BARBOSA, 1970; ARAÚJO et al., 1988; ARAÚJO \& GUIMARÃES, 1992; ANGOLA, 2011) e digitalizados (FAO, 2011), referentes aos seguintes temas: geologia; geomorfologia; hidrografia; solos; vegetação; rodovias, além de imagens de satélite (Google Earth $^{\mathrm{TM}}$ ). Para o processamento de todos os mapas e imagens utilizamos o software ArcGis ${ }^{\circledR}$, versão 10.0.

Fizemos ainda o levantamento de material bibliográfico pertinente e visitas a campo, em todas as áreas avaliadas, para o inventariamento expedito da fauna e flora, e verificação no local das características identificadas através das imagens analisadas.

Após o estudo detalhado dos mapas temáticos, imagens e dados obtidos das vistorias em campo de cada área, passamos a escolha dos elementos da paisagem mais adequados à caracterização de cada área para o fim previsto, ou seja, implementação de loteamentos urbanos. Utilizamos para tanto uma adaptação do Método Indireto das Componentes da Paisagem (GRIFFITH, 1979). Este método é definido por Pires (1993) como sendo a valoração realizada através da desagregação da paisagem e da análise de seus componentes, de acordo com diferentes juízos de valor e utilizando critérios de pontuação e classificação estabelecidos por especialistas. Griffith et al. (1997) sugerem, como levantamento básico para avaliação, os seguintes 
PORT, D. \& FISCH, F. Uso de elementos da paisagem como ferramenta...

componentes da paisagem: clima, geologia, geomorfologia, solos, recursos hídricos, vegetação, fauna, uso atual da terra, aspectos socioeconômicos, políticas públicas existentes para a área e recursos paisagísticos. Desta forma, selecionamos características do meio físico (tamanho da área; distância de curso de água; relevo); biótico (vegetação e fauna); e socioeconômico (uso do solo; distância de centro urbano; acessos), importantes para a avaliação da função para qual cada área foi destinada.

$\mathrm{Na}$ sequência, atribuímos valores individuais de qualidade para cada característica, definidos de forma subjetiva, de acordo com a importância de cada elemento da paisagem em relação ao uso futuro das áreas. A escala utilizada para a avaliação da qualidade da paisagem é composta por valores inteiros, equivalentes a $1,2,3,4$ e 5 , correspondendo às classes de qualidade baixa, média baixa, média, média alta e alta, respectivamente (LANDOVSKY et al., 2006) (Quadro 1).

\begin{tabular}{|c|c|c|c|c|c|c|}
\hline \multirow{2}{*}{ Meios } & \multirow{2}{*}{ Características } & \multicolumn{5}{|c|}{ Valores } \\
\hline & & $\begin{array}{l}\text { Alta } \\
(=5)\end{array}$ & $\begin{array}{c}\text { Média-alta } \\
(=4)\end{array}$ & $\begin{array}{c}\text { Média } \\
(=3)\end{array}$ & $\begin{array}{c}\text { Média-baixa } \\
(=2)\end{array}$ & $\begin{array}{c}\text { Baixa } \\
(=1)\end{array}$ \\
\hline \multirow{3}{*}{ Físico } & $\begin{array}{l}\text { Tamanho da área } \\
\text { (ha) }\end{array}$ & $>550$ & $400-550$ & $250-400$ & $100-250$ & $<100$ \\
\hline & \begin{tabular}{|l}
$\begin{array}{l}\text { Distância de curso } \\
\text { de água }(\mathrm{km})\end{array}$ \\
\end{tabular} & na área & $<1$ & $1-2$ & $2-3$ & $>3$ \\
\hline & $\begin{array}{l}\text { Relevo } \\
\text { (\% declividade) }\end{array}$ & $\begin{array}{l}\text { Plano } \\
(0 \text { a 3\%) }\end{array}$ & $\begin{array}{c}\text { suave } \\
\text { ondulado } \\
\text { (3 a 12\%) }\end{array}$ & $\begin{array}{l}\text { ondulado } \\
\text { (12 a } 24 \%)\end{array}$ & $\begin{array}{l}\text { forte ondulado } \\
(24 \text { a } 45 \%)\end{array}$ & $\underset{(>45 \%)}{\operatorname{montanhoso}}$ \\
\hline \multirow{3}{*}{ Socioeconômico } & Uso do solo & residencial & degradado & misto & agricultura & natural \\
\hline & \begin{tabular}{|l}
$\begin{array}{l}\text { Distância de centro } \\
\text { urbano }(\mathrm{km})\end{array}$ \\
\end{tabular} & $<1$ & $1-2$ & $2-3$ & $3-4$ & $>5$ \\
\hline & Acessos & muito fácil & fácil & moderado & difícil & muito difícil \\
\hline \multirow{2}{*}{ Biótico } & Vegetação nativa & muito pobre & pobre & média & rica & muito rica \\
\hline & Fauna nativa & muito pobre & pobre & média & rica & muito rica \\
\hline
\end{tabular}

Quadro 1: Valores atribuídos às características das áreas avaliadas.

Os critérios para a atribuição do valor de cada característica, por área, foram os seguintes: a) Tamanho da área em hectares (ha); b) Distância de curso de água: distância a partir do centro da área avaliada até o corpo hídrico mais próximo, em quilômetros $(\mathrm{km})$; c) Relevo (percentual de declividade): 0 a 3\%= plano; 3 a 12\%= 
PORT, D. \& FISCH, F. Uso de elementos da paisagem como ferramenta...

suave ondulado; 12 a $24 \%=$ ondulado; 24 a $45 \%=$ forte ondulado; e > 45\% montanhoso; d) Uso do solo: predominantemente residencial; área degradada; residencial e degradado; predominantemente agrícola; ambiente natural preservado; e) Distância de centro urbano: distância a partir do centro da área avaliada até a área urbana mais próxima, em quilômetros $(\mathrm{km}) ; \mathrm{f}$ ) Acessos: por via asfaltada; predominantemente por via asfaltada e com outros tipos de vias em bom estado de conservação; por vias não asfaltadas em bom estado de conservação; por vias não asfaltadas com razoável estado de conservação; por vias não asfaltadas em péssimo estado de conservação; g) Vegetação nativa: sem vegetação nativa; predominância de agricultura; áreas de vegetação nativa e áreas com outros usos; predominância de vegetação nativa; área preservada com vegetação nativa; h) Fauna (anfíbios, répteis, mamíferos, aves e invertebrados): apenas presença de um grupo; presença de dois grupos; presença de três grupos; presença de quatro grupos; presença de cinco grupos.

O total de pontos que uma determinada Reserva Fundiária poderá obter é de 40 pontos. Para verificação da adequação das áreas instituídas para a implantação de loteamentos, foi definido um índice de adequação, calculado pela seguinte equação:

$$
I A=\frac{V O}{V P} \times 100
$$

Onde, IA = índice de adequação (\%); VO = valor total obtido; e VP = máximo valor total possível.

Consideramos que uma área é inadequada para fins de loteamento urbano quando o valor do Índice de Adequação for menor ou igual a $50 \%$ (IA $\leq 50 \%$ ). Quando IA for maior do que $50 \%$ e menor do que $75 \%(50 \%<$ IA $>75 \%)$ consideramos a área adequada com restrições e quando o IA for maior ou igual a $75 \%$ (IA $\geq 75 \%$ ) consideramos a área adequada.

\section{Resultados e discussão}


PORT, D. \& FISCH, F. Uso de elementos da paisagem como ferramenta...

Atribuindo os valores propostos para as características de cada Reserva Fundiária avaliada obtivemos os resultados do Quadro 2.

\begin{tabular}{|l|l|ccccccc|}
\hline \multirow{3}{*}{ Meios } & \multirow{6}{*}{ Características } & \multicolumn{6}{|c|}{ Reservas Fundiárias/Valores } \\
\cline { 3 - 8 } & Sumbe & Sumbe I & $\begin{array}{c}\text { Porto } \\
\text { Amboim }\end{array}$ & $\begin{array}{c}\text { Waku } \\
\text { Kungo }\end{array}$ & Kibala & Amboim-Gabela \\
\hline \multirow{3}{*}{ Físico } & Tamanho da área & 5 & 4 & 3 & 2 & 2 & 4 \\
\cline { 2 - 8 } & $\begin{array}{l}\text { Distância de } \\
\text { curso de água }\end{array}$ & 1 & 3 & 4 & 5 & 2 & 1 \\
\cline { 2 - 9 } & Relevo & 4 & 4 & 3 & 5 & 1 & 2 \\
\cline { 2 - 9 } & Uso do solo & 3 & 3 & 3 & 2 & 1 & 3 \\
\hline \multirow{3}{*}{ Socioeconômico } & $\begin{array}{l}\text { Distância de } \\
\text { centro urbano }\end{array}$ & 1 & 3 & 4 & 3 & 4 & 4 \\
\cline { 2 - 9 } & Acessos & 5 & 5 & 5 & 4 & 2 & 4 \\
\hline \multirow{3}{*}{ Biótico } & Vegetação & 4 & 3 & 4 & 5 & 2 & 3 \\
\cline { 2 - 9 } & Fauna & 3 & 2 & 4 & 4 & 3 & 2 \\
\hline Total & & 26 & 27 & 30 & 30 & 17 & 23 \\
\hline Índice de Adequação (\%) & 65 & 67,5 & 75 & 75 & 42,5 & 57,5 \\
\hline
\end{tabular}

Quadro 2: Síntese dos valores obtidos, para as características da paisagem de cada Reserva Fundiária avaliada.

Analisando os resultados obtidos verificamos que, das seis Reservas Fundiárias avaliadas neste estudo, duas delas (Porto Amboim e Waku Kungo) poderiam ser consideradas adequadas para a implementação de loteamentos urbanos, uma vez que obtiveram um índice de adequação (IA) de 75\% cada. Outras três áreas (Sumbe, Sumbe I e Amboim-Gabela), apresentaram o IA de 65\%, 67,5\% e $57,5 \%$, respectivamente, e portanto, poderiam ser utilizadas para a atividade para a qual foram instituídas, porém com alguns cuidados que no caso de Sumbe referem-se às distâncias de corpos hídricos e centros urbanos, fatores estes que podem dificultar a implantação de infraestrutura neste local. Por sua vez, na área de Sumbe I, serão necessários maiores cuidados para evitar impactos na fauna nativa uma vez que esta área ainda abriga uma riqueza considerável, principalmente representantes de aves e répteis. No caso de Amboim- 
PORT, D. \& FISCH, F. Uso de elementos da paisagem como ferramenta...

Gabela, as principais restrições estão relacionadas à distância de recursos hídricos, o relevo (forte ondulado) e a riqueza de fauna ainda existente na área. Finalmente, a área Kibala, consideramos inadequada para a implantação de loteamentos urbanos $(\mathrm{IA}=42,5)$. Esta reserva é a que apresenta o pior conjunto de características para a implantação de loteamentos urbanos devido ao seu tamanho, distância de curso d'água, relevo (montanhoso), rochas aflorantes, difícil acesso e vegetação nativa preservada.

A partir da valoração dos componentes da paisagem verificamos que quanto maior o nível de integridade ambiental, em especial os componentes do meio físico e biótico, bem como a inexistência ou maior distância de infraestrutura urbana caracterizam as áreas inadequadas para fins de loteamentos urbanos. Por outro lado, áreas já degradadas ambientalmente por ação antrópica, próximas a centros urbanos já consolidados e com alguma infraestrutura, principalmente de acessos, são aquelas mais adequadas para receberem novos empreendimentos habitacionais.

Tal resultado seria o esperado e já havia sido verificado em outros trabalhos que constataram que a depleção de componentes naturais da paisagem torna-se o principal fator para depreciação paisagística de uma região (GRIFFITH, 1979, MILANO, 1990; ALVAREZ-ALFONSO, 1990; HARDT, 2000). Da mesma forma, zonas urbanizadas com elevado nível de degradação ambiental provocam a depreciação da paisagem (MARENZI, 1976; GRIFFITH, 1979; FORMAM \& GODRON, 1986; ALVAREZALFONSO, 1990; HARDT, 2000).

\section{Considerações finais}

Com base nos resultados obtidos, verificamos que no intuito de resolver um problema (déficit habitacional), é possível que os gestores venham a criar outros, principalmente relacionados a impactos sobre o ambiente natural, e técnicos, ligados à dificuldade de instalação da infraestrutura necessária nas diferentes áreas. 
PORT, D. \& FISCH, F. Uso de elementos da paisagem como ferramenta...

A incorporação de mecanismos de análise de paisagem no processo decisório de escolha de áreas para instalação de atividades antrópicas é uma ferramenta de grande valia, pois permite ao administrador público uma melhor avaliação das consequências ambientais e técnicas, em relação às escolhas feitas, eliminando áreas consideradas inadequadas e privilegiando aquelas com os melhores atributos para a finalidade prevista.

Acreditamos que trabalhos desta natureza possam orientar a avaliação e seleção de áreas potenciais à expansão urbana, visando, sobretudo, a redução de custos operacionais e ambientais.

\section{Referências bibliográficas}

ABREU, M. A. Evolução urbana do Rio de Janeiro. 2. ed. Rio de Janeiro: IPLANRIO/ZAHAR. 147 p, 1987.

ALVAREZ-ALFONSO, R. M. Estudio y valoración del paisage: território de Valderejo. Cantábria: Santander. Dissertação (Mestrado) - Universidad de Cantábria, Santander, 1990.

AMARAL, I. O Rio Cambongo-Negunza e os seus Afluentes: Um Exemplo da Complexidade de Padrões de Drenagem em Angola. Finisterra, Lisboa, v. XLI, n. 82, p. 15-48, 2006.

ANGOLA. Portal Oficial do Governo de Angola. 2011. Disponível em: $<\underline{\text { http://www.governo.gov.ao/> }}$. Acesso em: 29 nov. 2011.

ARAÚJO, A. G.; GUIMARÃES, F. Geologia de Angola. Notícia Explicativa da Carta Geológica a Escala 1:1.000.000. Instituto Nacional de Geologia. 137p,1992

ARAÚJO, A. G.; PEREVAlOF, O. V.; JUKOV, R. A. (coord.). Carta Geológica de Angola. Instituto Nacional de Geologia. Escala 1:1.000.000, 1988. 
PORT, D. \& FISCH, F. Uso de elementos da paisagem como ferramenta...

BARBOSA, L. A. G. Carta Fitogeográfica de Angola. Luanda: Instituto de Investigação Científica de Angola. 323p, 1970.

BOADI, K.; KUITUNEN, M.; RAHEEM, K.; HANNINEN, K. Urbanisation without Development: Environmental and Health Implications in African Cities. Environment, Development and Sustainability, Berlin, v.7, n. 4, p. 465-500, 2005.

DINIZ, A. C. Angola - o Meio Físico e Potencialidades Agrárias. Lisboa: Instituto da Cooperação Portuguesa. 189p, 1998.

DINIZ, A. C. Grandes Bacias Hidrográficas de Angola Recursos em terras com aptidão para o regadio - Rio Cunene. Lisboa: Instituto Português de Apoio ao Desenvolvimento. 174p, 2005.

FAO - Food and Agriculture Organization of the United Nations. FAO GeoNetwork. 2011. Disponível em: <http://www.fao.org/ geonetwork/srv/en/main.home>. Acesso em: 29 nov. 2011.

FLORIM, L. C.; QUELHAS, O. L. G. Contribuição para a Construção Sustentável: Características de um Projeto Habitacional Eco-Eficiente. ENGEVISTA, Rio de Janeiro, v. 6, n. 3, p. 121-120, 2004.

FORMAM, R. T. T.; GODRON, M. Landscape ecology. New York: John Wiley \& Sons. 619p, 1996.

GRIFFITH, J. J. Análise dos recursos visuais do parque da Serra da Canastra. Brasil Florestal. Brasília, v. 9, n. 40, p.13-21, 1979.

GRIFFITH, J. J.; JUCKSCH, I.; DIAS, L. E.; CÂMARA, J. B.; ARRUDA, M. B. 1997. Incorporação de Decisões Comunitárias sobre Zoneamento usando a Análise Gestalt da Paisagem. In: 
PORT, D. \& FISCH, F. Uso de elementos da paisagem como ferramenta...

CONGRESSO BRASILEIRO DE UNIDADES DE CONSERVAÇÃO, Curitiba. Anais... IAP: UNILIVRE: Rede Nacional Pro Unidade de Conservação. p.119-136, 1997.

HARDT, L. P. A. Subsídios à gestão da qualidade da paisagem urbana: aplicação a Curitiba, PR. Curitiba, Tese (Doutorado) Universidade Federal do Paraná, 2000.

LANDOVSKY, G. S.; BATISTA, D. B.; ARAKI, H. Análise da qualidade visual da paisagem da região de Tibagi, PR, aplicando o sensoriamento remoto. Revista Brasileira de Engenharia Agrícola e Ambiental. Campina Grande, v.10, n.1, p. 188-195, 2006.

MARENZI, R. C. Estudo da Valoração da Paisagem e Preferências Paisagísticas no Município da Penha - SC. Curitiba. Dissertação (Mestrado) - Universidade Federal do Paraná, 1996.

MILANO, M. S. Estudos da paisagem na avaliação de impactos ambientais. In: SEMINÁRIO SOBRE AVALIAÇÃO E RELATÓRIO DE IMPACTO AMBIENTAL, Curitiba. Anais... Curitiba: FUPEF, p. 117-125, 1990.

ROOSBROECK, V. P.; BETTENCOURT,J.; HUONGO, A. Actualização do perfil Ambiental de Angola. Framework Contract uropeAid/119860/C/SV/Multi - Lot $\mathrm{n}^{\circ}$ 6: Environment Specific Contract no 2006/116363. 87p, 2006.

ZEE-RJ. Zoneamento-Ecológico-Econômico-Rio de Janeiro. 2008. Disponível em: <http://zeerj.bem-vindo.net/portal/>, Acesso em: 30 jan. 2010 